\section{G431(P) AN AUDIT OF VACCINATION ADHERENCE AND ACCEPTABILITY OF OPPORTUNISTIC VACCINATION IN INPATIENT PAEDIATRICS}

${ }^{1}$ I Plumptre, ${ }^{2} \mathrm{~T}$ Tolppa, ${ }^{3} \mathrm{M}$ Blair. ${ }^{1}$ Department of Paediatrics, London North West Healthcare NHS Trust, London, UK; ${ }^{2}$ Department of Cardiology, London North West Healthcare NHS Trust, London, UK; ${ }^{3}$ River Island Academic Centre for Paediatrics and Child Public Health, Imperial College London, London, UK

\subsection{6/archdischild-2018-rcpch.420}

Aims Childhood immunisation constitutes an effective public health intervention to prevent serious infection, yet several areas of the UK fail to achieve the WHO target of $95 \%$ vaccination coverage. ${ }^{1-3}$ One strategy to improve the uptake of vaccination involves healthcare professionals identifying children in need of further immunisation and offering opportunistic vaccination. ${ }^{4-5}$ We aimed to assess local vaccination adherence rates and parent attitudes towards opportunistic vaccination. This aimed to determine the feasibility of implementing a process to identify and opportunistically vaccinate children during their inpatient stay.

Methods A questionnaire was designed and administered by a doctor to parents/guardians of paediatric inpatients aged five years and under at a district general hospital over a four-week period. Parents/guardians who spoke no English were excluded. Vaccination adherence was assessed by discussion with parents and counterchecked using the personal child health record (red book). Acceptability of opportunistic vaccination during inpatient stay or by the GP was asked using 'yes', 'no' or 'not sure' questions.

Results 50 eligible families participated. 42/50 (84.0\%) participants reported the child's vaccines were up to date (UTD), significantly below the WHO target $(\mathrm{p}=0.024)$. Of these, 14/ $50(28.0 \%)$ were verified by the red book. Verification was not possible in $29 / 50(58.0 \%)$ as the red book was missing. Rates for individual vaccines were (table 1 ):

\begin{tabular}{lll} 
Abstract $\mathbf{G 4 3 1 ( P )}$ Table 1 & \\
\hline Vaccine & Number missed & Percentage missed \\
\hline BCG & $5 / 50$ & $10.0 \%(\mathrm{p}=0.247)$ \\
12 week vaccines & $1 / 50$ & $2.00 \%$ \\
12 month vaccines & $3 / 50$ & $6.00 \%(\mathrm{p}=0.797)$ \\
3 year 4 month vaccines & $1 / 50$ & $2.00 \%$ \\
\hline
\end{tabular}

$2 / 42(4.76 \%)$ patients were identified as missing an immunisation (BCG) by checking the red book, despite parents reporting the child was UTD. 47/50 (94.0\%) participants considered it acceptable to have catch-up vaccines in hospital prior to discharge. $3 / 50(6.00 \%)$ reported 'not sure' due to limited spoken English. 48/50 (96.0\%) participants considered GP-led vaccination acceptable.

Conclusions The audit has determined that overall vaccination adherence is significantly below the WHO target of $95 \%$ within our population and that some families were unaware that their child was not UTD with their vaccinations. Children in our population would therefore benefit from identification and opportunistic vaccination offered during an inpatient stay, which is a strategy deemed acceptable by most families.

\section{REFERENCES}

1. Maciosek MV, Coffield AB, Edwards NM, Flottemesch TJ, Goodman MJ, Solberg LI. Priorities among effective clinical preventive services: Results of a systematic review and analysis. Am J Prev Med 2006;31:52-61.

2. WHO, UNICEF and World Bank. State of the world's vaccines and immunisation (3rd ed.) 2009. World Health Organisation: Geneva.

3. Public Health England. Quarterly vaccination coverage statistics for children aged up to five years in the UK (COVER programme): January to March 2017. Public Health England. Health Protection Report: Number 23, 2017.

4. Roland D, Ellis C, Blair ME. Assisting healthcare professionals in understanding drivers and barriers to improving pre-school immunisation uptake. Community Pract 2013;86:28-31.

5. Williams N, Woodward $H$, Majeed A, Saxena S. Primary care strategies to improve childhood immunisation uptake in developed countries: Systematic review. JRSM Short Rep 2011;2:81.

\section{G432(P) DEVELOPMENT OF SYMPTOM ASSESSMENT SERVICE AT A CHILDREN'S HOSPICE}

JM Balfe, M Cassidy, A Booth. LaurLynn, Ireland's Children's Hospice, Dublin, Ireland

\subsection{6/archdischild-2018-rcpch.421}

Background and aims High symptom burden has been recognised in children with life-limiting conditions (LLC) and symptom assessment and management is a core component of children's palliative care (CPC).

A previous audit highlighted a high prevalence of problematic symptoms in children accessing the hospice service prompting the development a symptom management team led by a paediatric consultant and CNS in CPC in spring 2016. All children in the earlier audited were in ACT category 3 and 4 and had diagnoses of severe disability with associated complex medical needs.

This report aims to describe the development of the service and provide data from the first year's activity.

Methods A record of all referrals to the team has been maintained since its inception. A retrospective chart review was performed and data was collected and recorded on an excel spreadsheet. Data recorded included description of problematic symptoms, team members involved and intervention required.

Results Referrals to the team are accepted from nursing and healthcare staff involved in the care of the child. A care pathway, symptom assessment tools and symptoms management plans have been developed.

To date 39 children have received support from the team, 7 of the children have died since referral. The CNS, wider nursing and multi-disciplinary team have supported all children referred. Medical assessment has been provided to 30 children. 25 children were offered a short break in the hospice to allow careful evaluation of symptoms using formal symptom assessment tools.

All children were provided with a symptom management plan and on-going support, at home, in the hospice or by telephone, individualised according to identified need. Parental and healthcare professional feedback has been positive.

Conclusion This report describes the initial establishment of a symptom assessment service in a children's hospice. The service has been developed in recognition of the high burden of problematic symptoms in children with severe disability and complex medical needs. It is anticipated that the service will continue to develop to meet the increasing needs of children with LLCs. 